\title{
Information Leaflet as an Adjunct to Verbal Counseling in Obtaining Informed Consent
}

\author{
Gangol R, 'Maharjan D² \\ 'Department of General Surgery, Patan Hospital, ${ }^{2}$ Department of General Surgery, Kathmandu Medical College Teaching \\ Hospital, Kathmandu, Nepal.
}

\section{ABSTRACT}

Introduction: This study evaluates if addition of information leaflet after the usual verbal counseling improves the level of understanding of patients undergoing surgery about their disease, the need for surgery and its complications.

Methods: It is a prospective observational case control study in which the control group receives verbal counseling only and the study group is given an information leaflet in addition to the verbal counseling after random allocation. An interviewer (surgical resident) interviews both the group using a set questionnaire. The answers are scored and added to give total marks.

Results: There were total 114 patients undergoing gall bladder surgery with 59 in the study group and 55 in the control group. The level of understanding was good or satisfactory in $18.2 \%$ in the control group compared to $76.3 \%$ in the study group $(\mathrm{P}<0.000)$. This statistically significant improvement was seen even among illiterate group when analyzed separately.

Conclusions: Addition of information leaflet significantly improves the patients understanding of their disease irrespective of their education status.

Key Words: education level, information leaflet, informed consent, understanding

\section{INTRODUCTION}

One of the current debates in legal and moral philosophy is about obtaining informed consent. Recently, there has been paradigm shift from orthodox doctor centered health care to patient centered treatment. ${ }^{1,2}$ These changes have come after hurdles of medico-legal cases, letting doctors to ponder upon their laggings. ${ }^{3}$ In most hospitals in Nepal doctors do the counseling but it's nurses who get the consent form signed. The signature is usually obtained from the relatives.

Correspondence:

Dr. Rajesh Gangol

Department of General Surgery

Patan Hospital, Lalitpur, Nepal.

Email: rajgongal@yahoo.com

Phone: 5545112 
A study in Patan hospital showed that level of understanding of patients undergoing a surgical procedure is good or satisfactory in only $56 \%$. Higher the education, better was the level of understanding. ${ }^{4}$ Other studies have also shown that comprehension of patients is poor ${ }^{5}$ and that addition of information booklet or videotape increased the level of patient's knowledge..$^{6.9}$ This study evaluates effect of reading information leaflet after the usual verbal explanation in the level of understanding of patients.

\section{METHODS}

A prospective observational case control study was conducted in Department of General Surgery; Patan Hospital from August, 2004 to November 2004. Approval for the study was obtained from the Hospital Administration.

All consecutive patients who were admitted for elective cholecystectomy were included.

Verbal consent was taken from the patients for the study. Once the patients had been counseled in the usual manner and consent form signed, the patients were randomly allotted to two groups according to computer generated random numbers. The study group was given information leaflet and the control group received verbal information during signing up informed consent. The leaflet had information about the disease, the need for surgery, the type of anaesthesia, the difference in laparoscopic procedure and the open procedure, the post-operative pain control measures, diet after the surgery and complications of surgery. This information was printed in Nepali.

All patients were asked a ten standard set of questions by the interviewing resident who gave each answer a point of two if they understood well, one point if the understanding was satisfactory and zero if the understanding was poor, maximum score of twenty and minimum of zero. If their total score was less than $25 \%$, they were said to have a poor understanding, a score of $26-50 \%$ was deemed unsatisfactory, $51-75 \%$ would be satisfactory and more than $75 \%$ was considered to be good. According to the education level, those unable to read and write were labeled as illiterate, those with education of one to three classes as primary, four to ten classes as secondary and more than ten classes as higher education status.

Comparison between mean score between two groups was calculated by using independent $\mathrm{t}$ - test and relation between dependent and independent variables by one way ANOVA with post HOC test by using 11.5 versions of SPSS. P value of 0.05 was taken as statistically significant.

\section{RESULTS}

There were total of 116 patients with 60 in the study group and 56 in the control group. Mean age was 45.5 in the study group and 42.5 in the control group. Male to female ratio was $1: 4$ in the study group and $1: 6$ in the control group.

Mean score of level of knowledge in those with information leaflet and verbal counseling was significantly higher $14.98 \pm 3.75$ than in patient who were only given verbal counseling $8.05 \pm 5.122$ ( $p$ value 0.000$)$.

The level of understanding in the control group showed that $36 \%$ had poor understanding, $31 \%$ had unsatisfactory, $20 \%$ had satisfactory and $13 \%$ had good understanding. The level of understanding in the study group i.e. after giving the information leaflet was poor in $3 \%$, unsatisfactory in $20 \%$, satisfactory in $36 \%$ and good in $41 \%$ (Figure 1 and 2).

Level Of Knowledge in patient with information leaflet
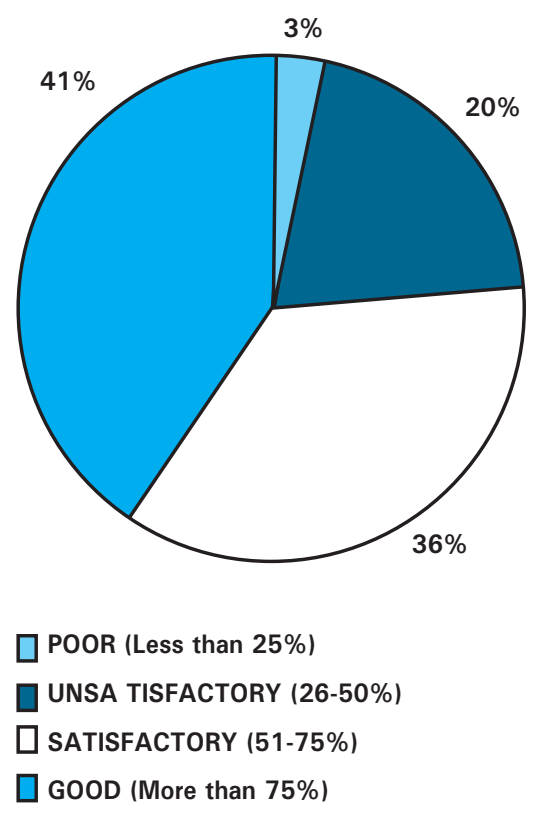

Figure 1. Level of knowledge in patient with information leaflet and verbal information

There was statistically significant difference among two groups when stratified according to different level of educations (Table 1). Analyzing the illiterate group separately also showed statistically significant improvement in the level of understanding after giving information leaflet ( $p$-value $=0.000$ ) (Table 2). 
Gangol et al. Information Leaflet as an Adjunct to Verbal Counseling in Obtaining Informed Consent

Table 1. Cross-tabulation between two groups according to different level of educations

\begin{tabular}{|c|c|c|c|c|c|c|c|}
\hline \multirow{2}{*}{$\begin{array}{l}\text { Education } \\
\text { Level }\end{array}$} & \multicolumn{7}{|c|}{ Level of Knowledge Score } \\
\hline & & Poor & Unsatisfactory & Satisfactory & Good & Total & P-value \\
\hline \multirow[t]{2}{*}{ Higher } & Case & 0 & 0 & 3 & 4 & 7 & 0.019 \\
\hline & Control & 3 & 2 & 1 & 0 & 6 & \\
\hline \multirow[t]{2}{*}{ Secondary } & Case & 1 & 3 & 8 & 9 & 21 & 0.008 \\
\hline & Control & 5 & 7 & 2 & 2 & 16 & \\
\hline \multirow[t]{2}{*}{ Primary } & Case & 0 & 0 & 3 & 2 & 5 & 0.161 \\
\hline & Control & 1 & 1 & 0 & 1 & 3 & \\
\hline \multirow[t]{2}{*}{ Illiterate } & Case & 1 & 9 & 7 & 9 & 26 & 0.000 \\
\hline & Control & 15 & 11 & 3 & 1 & 30 & \\
\hline \multirow[t]{2}{*}{ Total } & Case & 2 & 12 & 21 & 24 & 59 & \\
\hline & Control & 24 & 21 & 6 & 4 & 55 & \\
\hline
\end{tabular}

Table 2. Cross tabulation amongst two groups in illiterate group

\begin{tabular}{lccccc}
\hline \multicolumn{5}{c}{ Level of understanding } \\
\hline & Poor (\%) & Unsatisfactory (\%) & Satisfactory (\%) & Good (\%) & Total (\%) \\
$\begin{array}{l}\text { With Information } \\
\text { Leaflet }\end{array}$ & $1(3.8)$ & $9(34.6)$ & $7(26.9)$ & $9(34.6)$ & $26(100)$ \\
$\begin{array}{l}\text { With Verbal } \\
\text { Information Only }\end{array}$ & $15(50)$ & $11(36.7)$ & $3(10)$ & $1(3.3)$ & $30(100)$ \\
Total & $16(28.6)$ & $20(35.7)$ & $10(17.9)$ & $10(17.9)$ & $56(100)$ \\
\hline
\end{tabular}

\section{DISCUSSION}

The results of this study show that there is a statistically significant improvement in the level of understanding on providing information leaflet. This is true for all patients irrespective of their level of education. There was significantly better understanding even in the illiterate group which was provided with the information leaflet in comparison to those who were given just verbal information. This is likely to be due to a family member who is literate and reads the information to the patient. Even in the literate group, whose level of understanding is better to begin with, the subgroup that was given the leaflet had better understanding.

The limitation of this study is that the method of testing has not been validated. Our assumption is that this method is similar to viva voce examination that is conducted in all spheres of education and which has stood the test of time. Many other studies have also used similar methods; some, however, using written questionnaire which has to be filled by the individuals. ${ }^{10,11}$ We did not use this because there were many patients in our study group who were not able to read or write.
Another limitation of this study is that only short terms recall memory is tested. Whether the addition of information leaflet improves the recall of the facts given at the time of taking informed consent in two weeks or later is not known. Similarly, we have not assessed about presentation of information in the leaflet according to SMOG readability score. ${ }^{12}$

Irrespective of the limitations, this study clearly adds strength to the discussion that the patients' understanding of their disease process and the need for surgery, its complications are not understood well as shown by the results of the control group. It also proves that addition of information leaflet in simple language greatly helps in the understanding. The information booklet should not replace verbal explanation given by the physician.

\section{CONCLUSIONS}

Patient information leaflet is a valuable adjunct to verbal counseling, increasing the level of understanding of the disease and its complications in patients of all level of educational background and hence, should be used in day to day work of health care delivery. 


\section{REFERENCES}

1. General Medical Council. Seeking patients' consent: the ethical considerations London: GMC; 2001.

2. General Medical Council. Consent: patients and doctors making decisions together. London: GMC; 2008.

3. British Medical Association. Medical ethics today. Its practice and philosophy. London; BMA; 1993.

4. Gongal R, Bhattarai P. Informed consent: Is it really understood? Kathmandu Univ Med J. 2005;3:271-3.

5. Rogers AE, Addington-Hall JM, Abery AJ, McCoy AS, Bulpitt C, Coats AJ, et al. Knowledge and communication difficulties for patients with chronic heart failure: qualitative study. BMJ. 2000;321:605-7.

6. Maberry Mk, Mayberry JF. Towards better informed consent in endoscopy: a study of information and consent processes in gastroscopy and flexible sigmoidoscopy. Eur J Gastroenterol Hepatol. 2001 Dec;13(12):1467-76.

7. Agre P, McKee K, Gargon N, Kurtz RC. Patient satisfaction with an informed consent process. Cancer Pract. 1997 MayJun;5(3):162-7.
8. Eaden J, Abrams K, Shears J, Mayberr J. Randomized controlled trial comparing the efficacy of a video and information leaflet versus information leaflet alone on patient knowledge about surveillance and cancer risk in ulcerative colitis. Inflamm Bowel Dis. 2002 Nov;8(6):407-12.

9. Kearns S, Kingston R, Forman S, Murray P. How informed is consent? Use of an information booklet in patients undergoing total hip replacement. Ir Med J. 2001 Jun;94(6):171-2.

10. Kriwanek S, Armbruster C, Beckerhinn P, Blauensteier W, Gschwantler M. Patients' assessment and recall of surgical information after laparoscopic cholecystectomy. Dig Surg. 1998;15:669-73.

11. Ashraff S, Malawa G, Dolan T and Khanduja V. Prospective randomized controlled trial on the role of patient information leaflets in obtaining informed consent. ANZ J Surg. 2006;76:139-41.

12. McGraw HC. SMOG Grading: A new readability formula. J Reading. 1969;12:639-46. 